\title{
Prevalence of Carpal Tunnel Syndrome in Auto-Rickshaw Drivers
}

\author{
Amruta Kadam ${ }^{1}$, Gargi Bhalekar ${ }^{2}$ \\ ${ }^{1}$ Intern, LSFPEF College of Physiotherapy, Pune, India. \\ ${ }^{2}$ Professor of Neuro Physiotherapy, LSFPEF College of Physiotherapy, Pune, India \\ Corresponding Author: Amruta Kadam
}

\begin{abstract}
Background: The carpal tunnel is a rigid, confined fibro- osseous space that physiologically acts as a 'closed compartment'. Carpal tunnel syndrome is characterized by the sensory and motor weakness that occurs when the median nerve is compressed in the carpal tunnel. The clinical syndrome is characterized by pain, numbness, or tingling in the distribution of median nerve. Carpal tunnel syndrome occurs as a result of repetitive or sustained wrist flexion, extension or gripping activities. Driving auto-rickshaws involves repetitive movement of the wrist, specifically flexion and extension, so it may increase the risk of carpal tunnel in these populations.
\end{abstract}

Purpose: To find the prevalence of carpal tunnel syndrome in auto-rickshaw drivers

Methods: 100 auto-rickshaw drivers were selected based on the inclusion and exclusion criteria. Convenient sampling was done. Ethical approval was taken prior to the study. Data was collected by a self- made questionnaire which was validated. Special confirmatory test (Phalen's test and Carpal compression test) was performed.

Results: The result showed that out of 100 auto-rickshaw drivers 23 subjects had pain, tingling and numbness, 16 subjects had weakness, 10 subjects had pain at night. Majority of the population i.e. 50 subjects were driving for 7-10 hours and for more than 10 years. Out of 23 subjects experiencing symptoms 18 subjects had been experiencing the symptoms since last 2 years, 9 subjects felt the symptoms at the end of driving, while 7 subjects said that there was relief in symptoms after taking rest. Out of 100 subjects 23 subjects were tested positive for Phalen's and carpal compression test.

Conclusion: This study concludes that there is $23 \%$ prevalence of carpal tunnel syndrome in autorickshaw drivers.

Keywords: Carpal tunnel syndrome, Auto-rickshaw drivers, Cumulative trauma disorder

\section{INTRODUCTION}

Globally occupational health sector is demanding more attention from the health care authorities by each passing day, since disorders that follow due to work environment have gradually increased in types and magnitude and have led to aggravated diseases affecting large number of workers. The economic growth in India is being marked by an inevitable increase in transportation activities of all sectors. In case of total passenger transportation, almost $80 \%$ of the load is shared by road transport sector. ${ }^{(1)}$
The city is highly populated with most of the roads poorly maintained. ${ }^{(2)}$

People working in transport sector spend more than 8-10 hours a day in traffic.

Auto-rickshaws are an important part of urban mobility and a step to improving sustainable transportation as well as quality of life in Indian cities.

Auto-rickshaws also bridge the gap between public transport and door to door services providing an alternative to private vehicles and also their availability at any time of day and night, and their affordability 
of services makes auto an important object of the system.

There are many problems in the wrist due to overuse of the wrist joint and peri-articular structures.

Chronic overuse of the wrist causes increase in pressure in flexor retinaculum of the wrist. $^{(3)}$

The carpal tunnel is a rigid, confined fibroosseous space that physiologically acts as a 'closed compartment'. ${ }^{(4)}$

Carpal tunnel syndrome is characterized by the sensory and motor weakness that occur when the median nerve is compressed in the carpal tunnel. ${ }^{(5)}$

The clinical syndrome is characterized by pain, numbness, or tingling in the distribution of median nerve. ${ }^{(4)}$

These symptoms may affect all or combination of the thumb, index, long and ring finger. ${ }^{(4)}$

Carpal tunnel syndrome occurs as a result of repetitive or sustained wrist flexion, extension or gripping activities. ${ }^{(5)}$

Therefore carpal tunnel syndrome is classified as a cumulative trauma or overuse syndrome. ${ }^{(5)}$

\section{Occupational Carpal tunnel syndrome}

A syndrome of hand and wrist numbness or paresthesia due to entrapment of the median nerve caused by ones occupation.

\section{MATERIALS AND METHODS}

Type of study - Observational

Sampling technique - Convenient sampling
Sample size - 100 auto-rickshaw drivers

Study area - PCMC

Population - Auto-rickshaw drivers

Study duration - One time study

Outcome measures - 1. Self-made

questionnaire. 2. Special test

Inclusion Criteria

1. Auto-rickshaw drivers in PCMC area

2. Males and females

3. Age group- 20-40yrs

Exclusion Criteria

1. Recent fracture of the wrist

2. Deformities of the hand and wrist

3. Any other soft tissue injury of the hand

4. Pregnant ladies

5. Collagen diseases

6. Metabolic disease

7. Any recent trauma

\section{PROCEDURE}

Ethical approval was taken from the ethical committee. A questionnaire was prepared and distributed among 10 physiotherapists for validation. Subjects were chosen on the basis of inclusion and exclusion criteria. Written and signed consent was taken from the participants. The questionnaire was explained to the participants. Special test was explained and performed on the participants.

\section{STATISTICAL ANALYSIS}

1. Graph 1 shows the number of population experiencing pain, tingling, numbness and weakness in wrist and hand while driving.

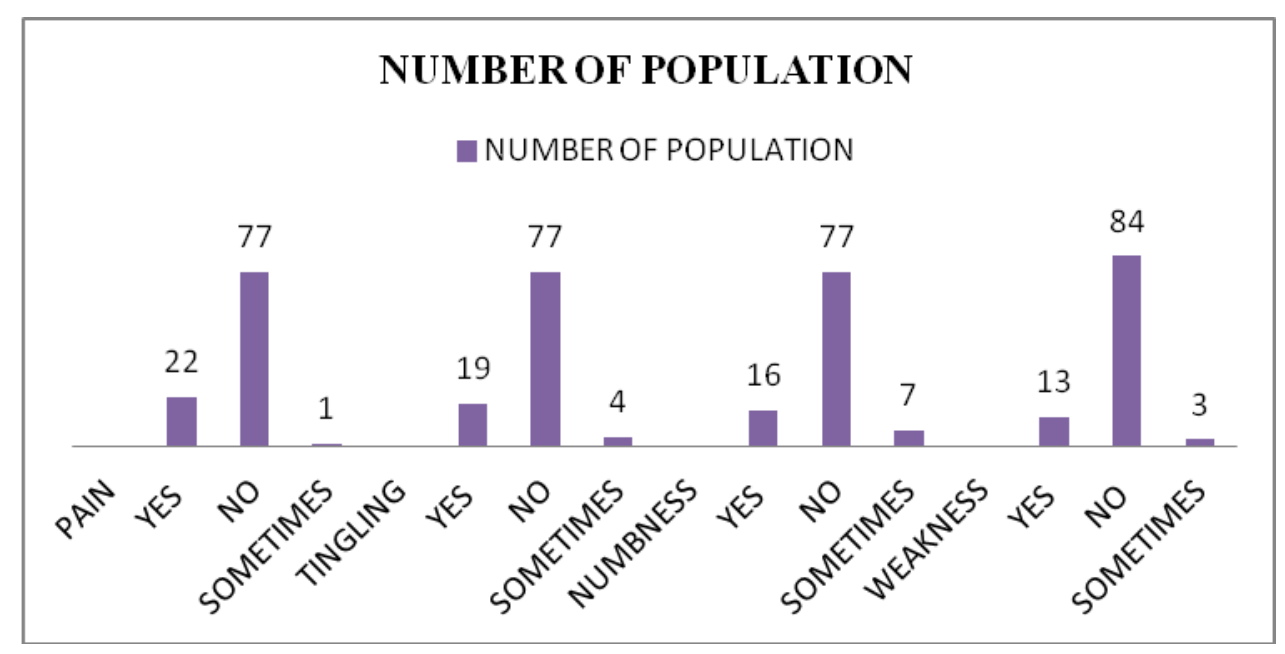




\section{Interpretation}

Graph 1 shows that out of 100 subjects

22 subjects were having pain in the wrist while driving, 1 subject experienced pain for sometime while 77 subjects were having no pain in the wrist and hand while driving.

19 subjects were having tingling sensation in the hand while driving, 4 subjects were having tingling for sometime, while 77 subjects were having no tingling sensation in the wrist or hand while driving.
16 subjects were having numbness in the wrist or hand while driving, 7 subjects were having numbness for sometime, while 77 subjects were not having numbness in the wrist or hand while driving.

13 subjects were having weakness in the wrist or hand while driving, 3 subjects were having weakness for sometime, while 84 subjects were not having weakness in the wrist or hand while driving.

\section{Graph 2 shows the site of tingling sensation while driving}

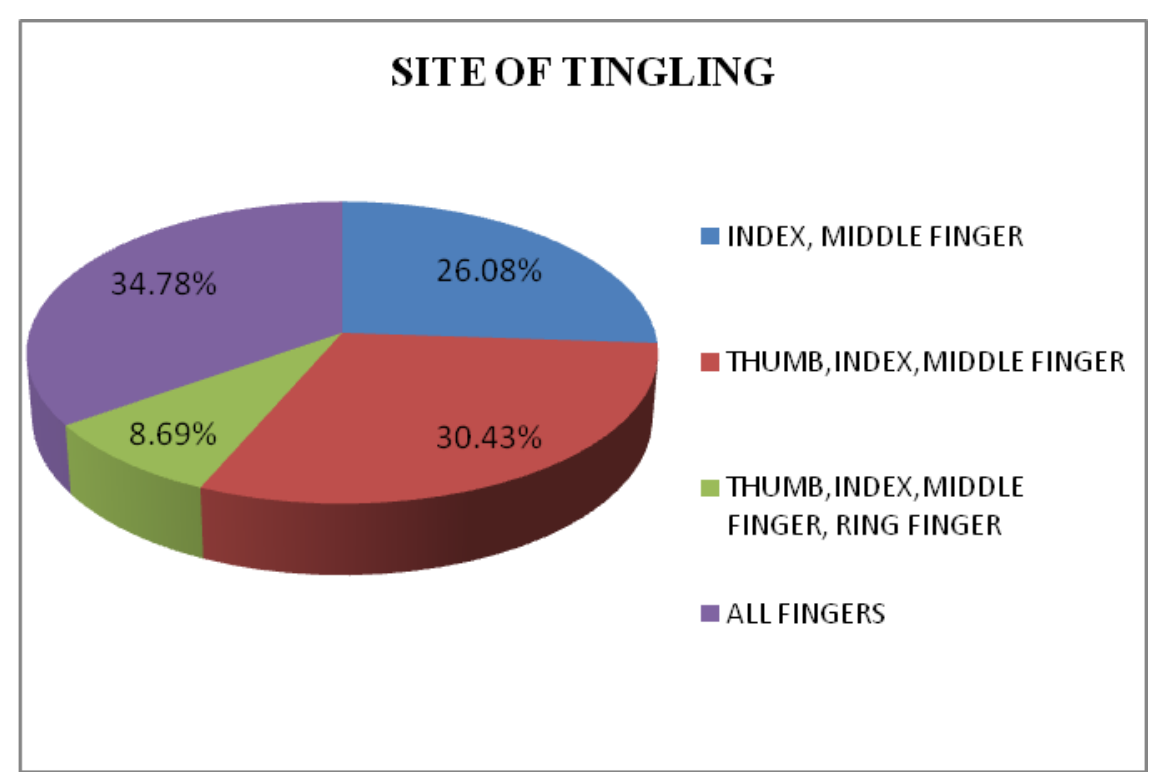

\section{Interpretation}

Graph 2 shows that out of $23 \%$ of population experiencing tingling sensation

$2(8.69 \%)$ population is having tingling sensation in thumb, index, middle and ring finger

$6(26.08 \%)$ population is having tingling sensation in index and middle finger

7 (30.43\%) population is having tingling sensation in thumb, index and middle finger

$8(34.78 \%)$ population is having tingling sensation in all fingers.
3. Graph 3 shows number of population having pain at night

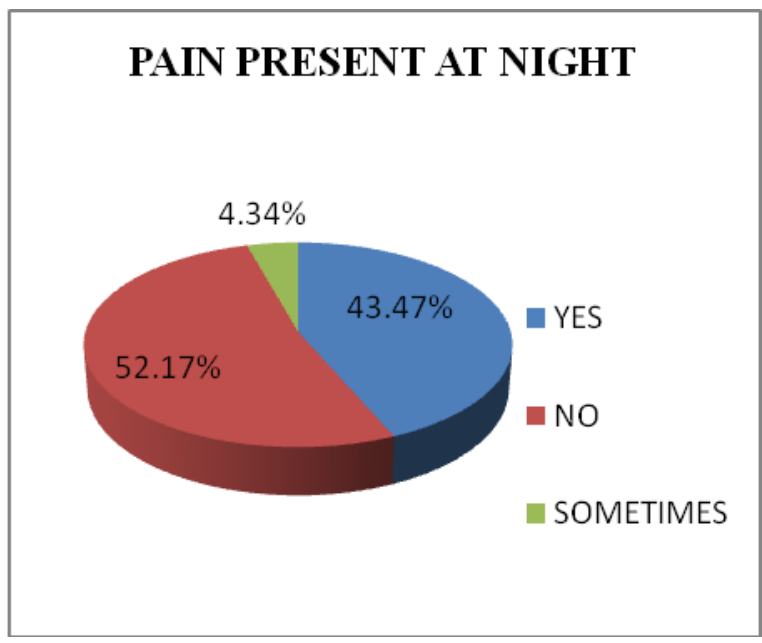

\section{Interpretation}

Graph 3 shows that out of $23 \%$ of population experiencing pain, $10(43.47 \%)$ 
of population is having pain at night, $1(4.34 \%)$ population is having pain sometimes, $12(52.17 \%)$ of population is not having pain at night.

\section{Graph 4 shows the duration of driving}

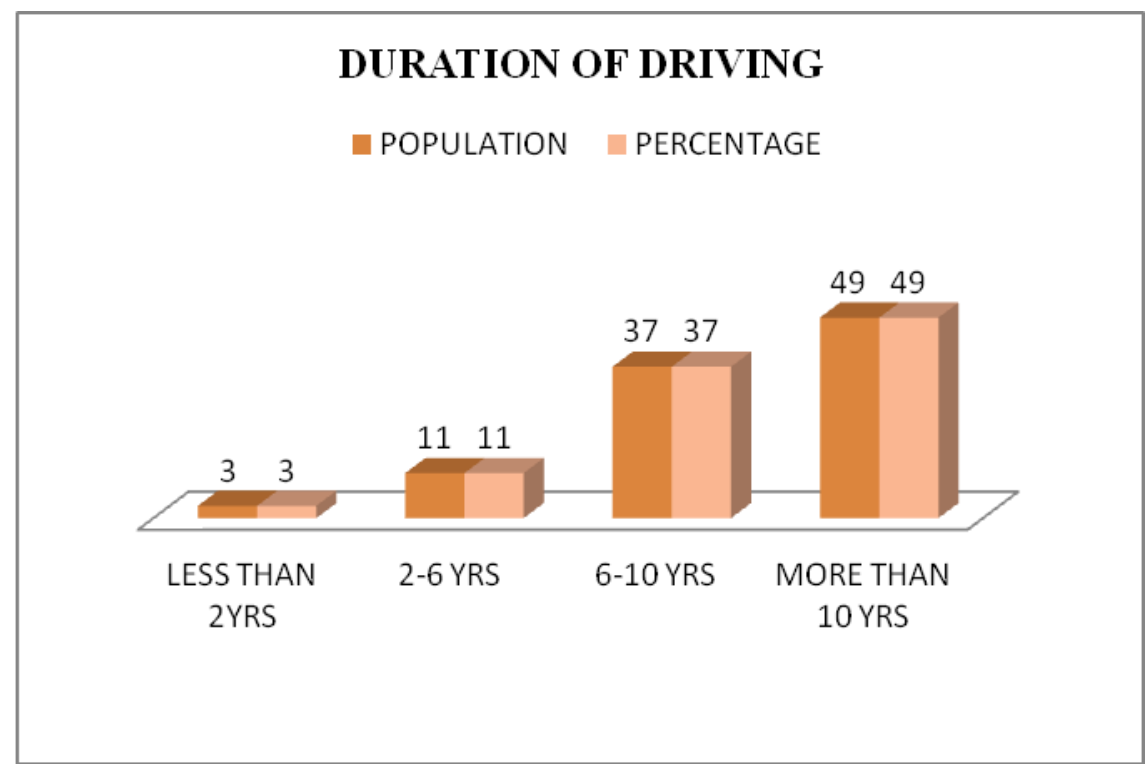

\section{Interpretation}

Graph 4 shows that

$3 \%$ of population have been driving for less than 2 years

$11 \%$ of population have been driving for 2-6 years.

$37 \%$ of population have been driving for 6-10 years.

$49 \%$ of population have been driving for more than 10 years.

\section{Graph 5 shows daily hours of driving}

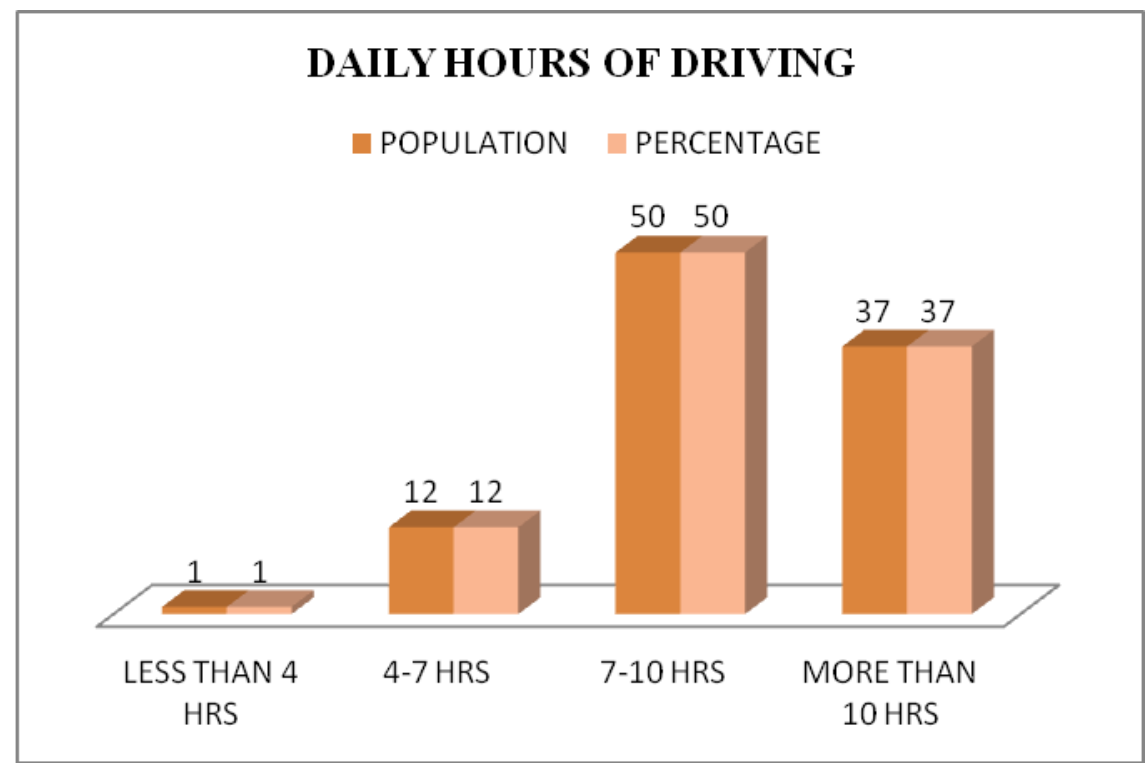

Interpretation

Graph 5 shows that

$1 \%$ of population have been driving for less than 4 hours. 
$12 \%$ of population have been driving for 4-7 hours.

$50 \%$ of population have been driving for 7-10 hours.

$37 \%$ of population have been driving for more than 10 hours

\section{Graph 6 shows from how much duration the symptoms are present}

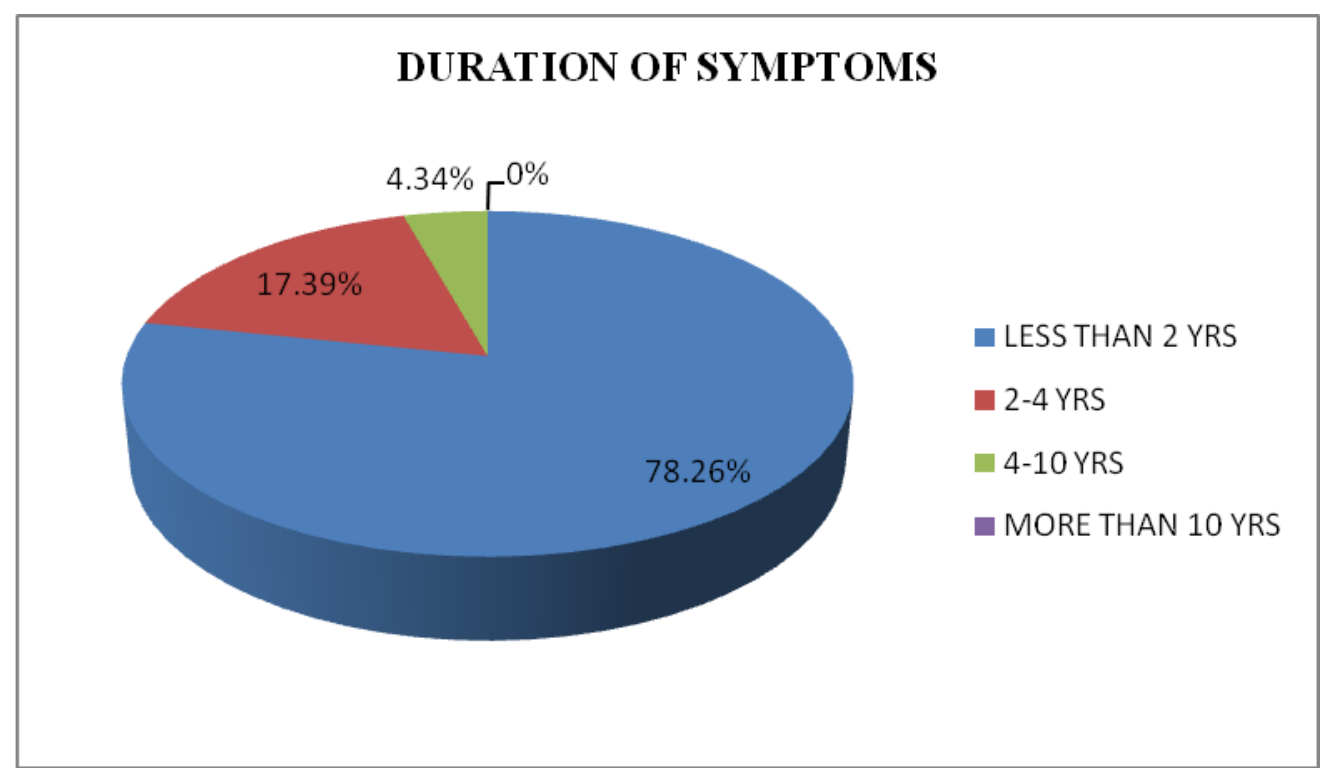

\section{Interpretation}

Graph 6 shows that out of $23 \%$ of population having symptoms

$18(78.26 \%)$ of population have been experiencing the symptoms for less than 2 years.

$4(17.39 \%)$ of population have been experiencing the symptoms from 2-4 years.

$1(4.34 \%)$ of population have been experiencing the symptoms from 4-10 years.

\section{Graph 7 shows that when are the extremes of symptoms felt while driving}

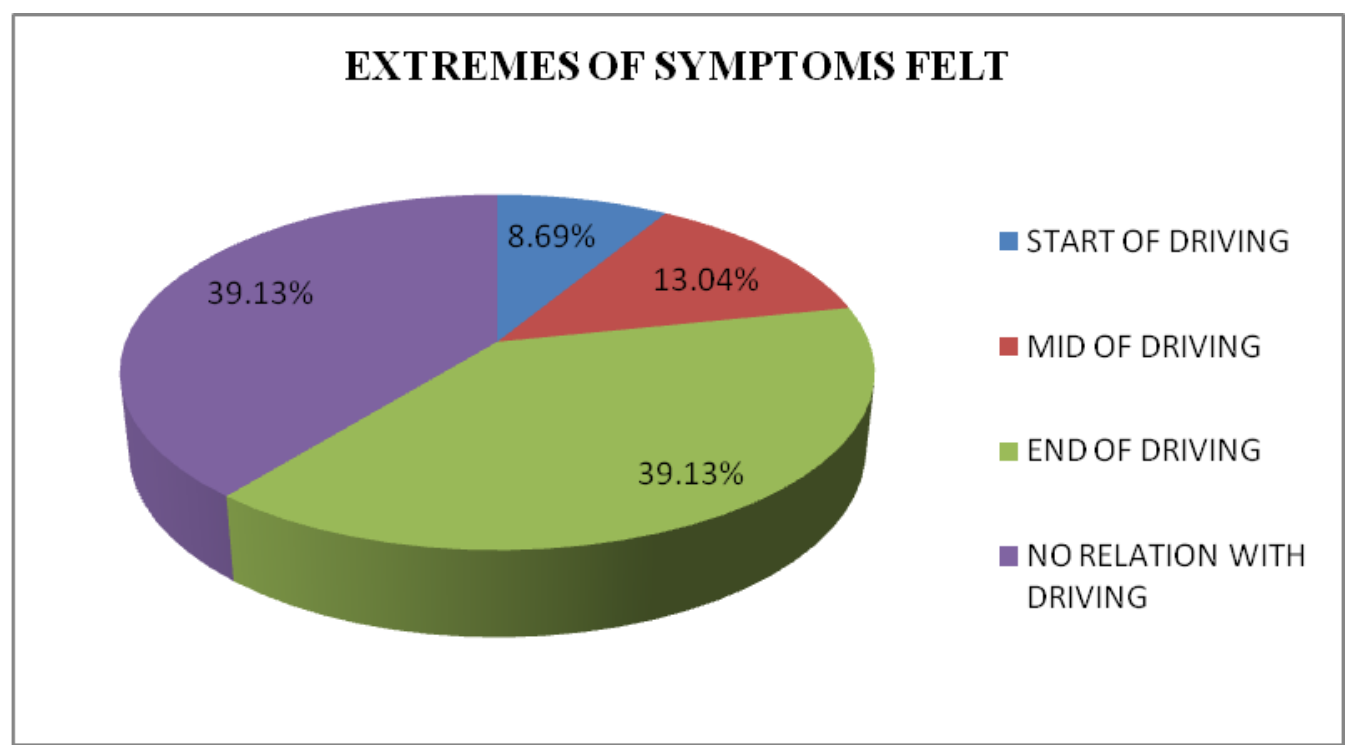

\section{Interpretation}

Graph 7 shows that out of $23 \%$ of population experiencing symptoms

$2(8.69 \%)$ of population have been experiencing extremes of symptoms at the start of driving. 
$3(13.04 \%)$ of population have been experiencing extremes of symptoms at the mid of driving.

$9(39.13 \%)$ of population have been experiencing extremes of symptoms at the end of driving.

$9(39.13 \%)$ of population is not having relation of symptoms with driving

\section{Graph 8 shows number of population taking rest and their duration of rest interval}

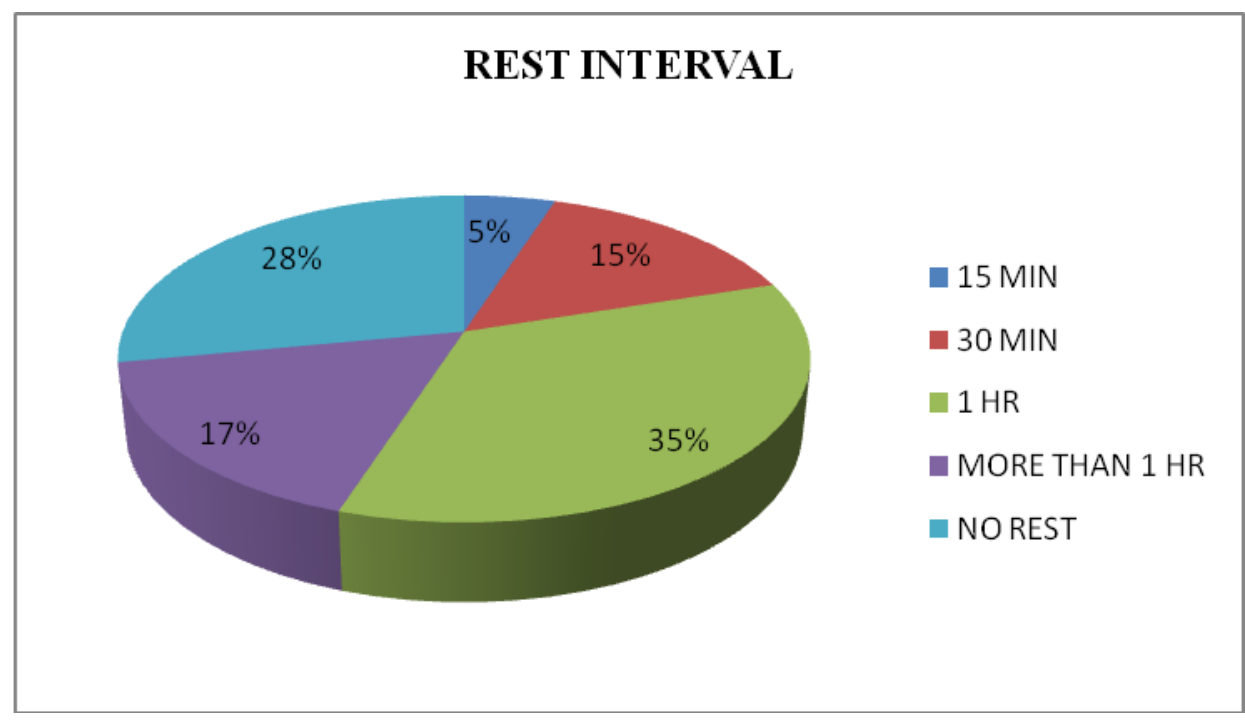

\section{Interpretation}

Graph 8 shows that out of 100 subjects

5 subjects were taking rest for 15 mins, 15 subjects were taking rest for 30 mins, 35 subjects were taking rest for 1 hour, 17 subjects were taking rest for more than 1 hour while 28 subjects were not taking rest interval.

9. Graph 9 shows whether there is relief in symptoms after taking rest

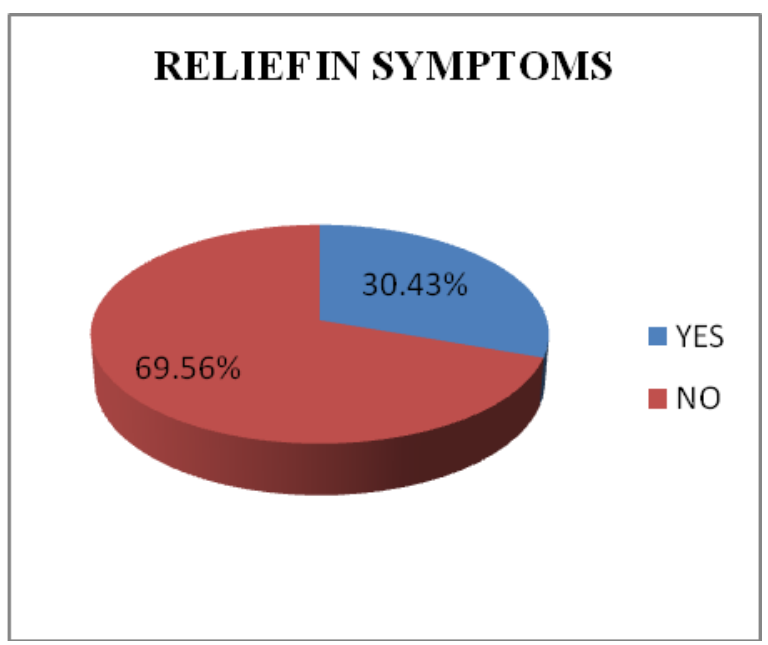

\section{Interpretation}

Graph 9 shows that out of $23 \%$ of population experiencing symptoms $7(30.43 \%)$ of population have relief in symptoms after taking rest.

$16(69.56 \%)$ of population have no relief in symptoms after taking rest.

10. Graph 10 shows number of population in which Phalen's test is positive

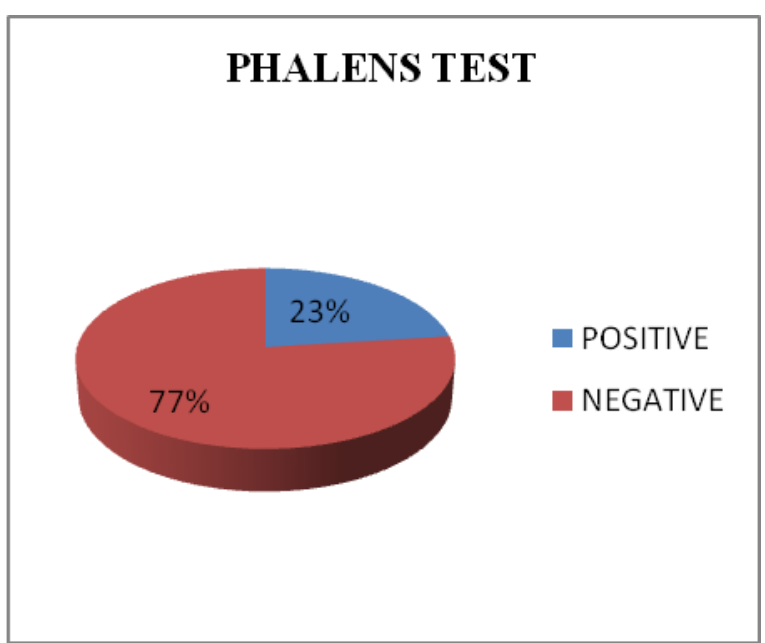




\section{Interpretation}

Graph 10 shows that $23 \%$ of population have positive Phalen's test and $77 \%$ is having negative Phalen's test.

11. Graph 11 shows number of population in which carpal compression test is positive

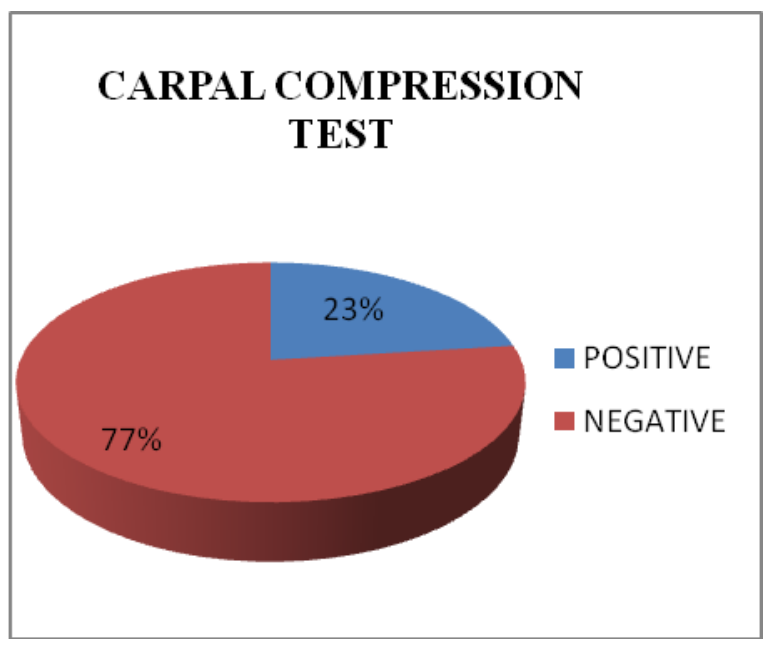

\section{Interpretation}

Graph 11 shows that $23 \%$ of population have positive carpal compression test and $77 \%$ is having negative carpal compression test.

\section{RESULT}

A total of 100 samples were taken in this study, which included male autorickshaw drivers between the age group of 20-40 years. Questionnaire was asked and special test was performed on every individual.

Based on the statistical analysis,

Graph 1 shows that $22 \%$ of population experienced pain in the wrist or hand while driving, $1 \%$ experienced pain for sometime while $77 \%$ population had no pain, $19 \%$ of population had tingling sensation in the hand while driving, $4 \%$ experienced tingling for sometime while $77 \%$ population had no tingling. $16 \%$ population were having numbness in the wrist or hand while driving, $7 \%$ population had numbness for sometime while $77 \%$ population had no numbness while driving, $13 \%$ population were having weakness in the wrist or hand driving, 3\% were weakness for sometime while $84 \%$ population were not having weakness in the wrist or hand while driving.

Graph 2 represents that out of $23 \%$ of population experiencing tingling $26.08 \%$ had tingling in index and middle finger, $30.43 \%$ had tingling in the thumb, index, and middle finger, $8.69 \%$ had tingling in the thumb, index, middle and ring finger, $34.78 \%$ had tingling in all the fingers.

Graph 3 represents that out of $23 \%$ of population having pain, $10(43.47 \%)$ experienced pain at night, while $1(4.4 \%)$ population had pain for sometime.

Graph 4 shows that majority i.e. $49 \%$ population were driving auto for more than 10 years, $37 \%$ were driving for $6-10$ years, $11 \%$ for $2-6$ years and $3 \%$ for less than 2 years.

Graph 5 shows that majority of population i.e. $50 \%$ were driving for 7-10 hrs, $1 \%$ for less than $4 \mathrm{hrs}, 12 \%$ for $4-7 \mathrm{hrs}$ and $37 \%$ for more than $10 \mathrm{hrs}$.

Graph 6 shows that out of $23 \%$ of population having symptoms $18(78.26 \%)$ were experiencing it since last 2 yrs, $4(17.39 \%)$ were experiencing from 2-4 yrs, $1(4.34 \%)$ were experiencing the symptoms 4-10 years.

Graph 7 shows that out of $23 \%$ population having symptoms $9(39.13 \%)$ population felt the symptoms at the end of driving, $2(8.69 \%)$ felt the symptoms at the start of the driving, $3(13.04 \%)$ at the mid of driving, $9(39.13 \%)$ said that there was no relation with driving.

Graph 8 represents that out of 100 auto-rickshaw drivers 5 subjects were taking rest for 15 minutes, 15 subjects were taking rest for 30 minutes, 35 subjects were taking rest for 1 hour, 17 subjects were taking rest for more than 1 hour while 28 subjects were no taking rest interval.

Graph 9 shows that $7(30.43 \%)$ population has relief in symptoms after taking rest.

Graph 10 and 11 represents that 23\% of population have positive Phalen's and carpal compression test. 


\section{DISCUSSION}

The carpal tunnel is a confined space between the carpal bones dorsally and the transverse carpal ligament volarly. In this region, the median nerve is susceptible to pressure as it courses through the tunnel with the extrinsic finger flexor tendons on their way into the hand. Anything that decreases the space in the carpal tunnel or causes the contents of the tunnel to enlarge could compress or restrict the mobility of the median nerve.

It has long been recognized that workers with predominantly repetitive tasks, or those maintaining fixed postures of time, have an increased risk of developing workrelated musculoskeletal illness. ${ }^{(16)}$

Driving auto-rickshaws involves repetitive movement of the wrist, specifically flexion and extension while accelerating and intense gripping while applying the brakes.

These repetitive motions elevate the pressure inside the carpal tunnel, which may diminish blood flow to the median nerve and cause blocking of the nerve. ${ }^{(17)}$

When the hand is placed in a position outside of its neutral position, it causes the tendons to rub against the walls of the carpal tunnel and cause friction. The tendons of the wrist are surrounded by a synovial membrane which secrets synovium, a lubricating fluid. When friction is present, the membrane produces fluid to limit the friction. However, since the wrist only has a certain amount of space the swelling reduces the space of the carpal tunnel, compressing the median nerve. ${ }^{(17)}$

The purpose of my study was to find out the prevalence of carpal tunnel syndrome in auto-rickshaw drivers through a self- made questionnaire and special test.

Many studies have suggested that age plays a significant role in Carpal tunnel syndrome, several study agree that risk of carpal tunnel syndrome increase after the age of 30 since it is a cumulative trauma disorder. ${ }^{(16,18)}$

Similarly, in the present study, $71 \%$ population is above the age of 30 years.
Based on the questionnaire 23\% population had pain in the wrist or hand while $77 \%$ population had no pain in the wrist or hand while driving. $23 \%$ population had tingling, $23 \%$ had numbness, $16 \%$ population had weakness, $4 \%$ had restriction of movement, while $11 \%$ were having nocturnal pain.

Awkward wrist postures such as working with joints near their end range of motion; uneven loading and static muscle activity are all risk factors in the development of Carpal tunnel syndrome

They increase the biomechanics stress on the muscles and the surrounding joint tissues. This causes pain in the hand, unpleasant tingling, pain or numbness in the distal distribution of the median nerve and a reduction of grip strength and function of the affected hand. ${ }^{(17)}$

The study done by Scott Barnhart Carpal tunnel syndrome among ski manufacturing workers in 1991 used a used a cross-sectional study incorporating electrophysiological tests, physical examinations, and questionnaires to compare the prevalence of carpal tunnel syndrome between workers with jobs classified as repetitive and those with nonrepetitive jobs. The result showed that pain, paresthesias, or nocturnal pain were more common in either or both hands among the subjects with repetitive jobs than among those with non-repetitive job. The subjects with repetitive jobs had Phalen's sign more frequently than those with non-repetitive jobs.

In the study done by Hagbergm, Morgensternh, Kelsh $\mathrm{M}$ on Impact of occupations and job tasks on the prevalence of carpal tunnel syndrome in 1992 showed that highest prevalence was noted for grinders, butchers, grocery store workers, frozen food factory workers, platers, and workers with high-force, high-repetitive manual movements. On the basis of epidemiologic and other evidence, it concluded that exposure to physical work load factors, such as repetitive and forceful 
gripping, is probably a major risk factor for CTS in several types of worker populations.

According to the present study people who were having these signs and symptoms were driving for 4-7 hours \&/or more than 10 hours daily and have been driving for last 6-10 years or more than 10 years.

They were experiencing these symptoms from last 2 years, while $9 \%$ of population felt the extremes of symptoms at the end of driving, 9\% said that there is no relation between the duration of driving and the signs and symptoms.

Out of $23 \%$ population having signs and symptoms, $18 \%$ were taking rest while $5 \%$ were not taking rest; in which $7 \%$ population had relief in symptoms after taking rest, $10 \%$ had no relief in symptoms even after taking rest, while $1 \%$ said that there is no relation between the signs and symptoms and rest.

When force is applied repeatedly over a prolonged period to the tendons found in the carpal tunnel, the cumulative forces may cause soft-tissue micro-tears and trauma. ${ }^{(17)}$

Phalens test and carpal compression test are special diagnostic test used for confirmation of Carpal tunnel syndrome. In the above study $23 \%$ population had positive phalens and carpal compression test.

\section{CONCLUSION}

This study concludes that there is $23 \%$ prevalence of carpal tunnel syndrome in auto-rickshaw drivers.

\section{Limitations of study}

1. Age can be a limitation for this study.

2. Data was collected from a limited place that limited generalizability of result.

3. Small sample size were included in this study.

\section{Future scope of study}

1. The study can be done in large sample size.
2. The study can be conducted at different locations.

3. The study can be done in different age group.

4. Females can also be included.

5. Further studies can be done on autorickshaw drivers to check the severity of carpal tunnel syndrome using NCV.

\section{Acknowledgement: None}

\section{Conflict of Interest: None}

\section{Source of Funding: None}

\section{Ethical Approval: Approved}

\section{REFERENCES}

1. Anupriya P. Mohokar conducted study on prevalence \& risk factors of musculoskeletal impairments among auto-rickshaw drivers in a city of central India. e-ISSN: 22790853, P-ISSN: 2279-0861. Volume 17, Issue 2 Ver. 3 February . (2018), PP49-54 www.iosrjournals.org

2. Rahul Shaik, Christie Kiran Gotru, Chintada Ganapathi Swamy, R. Sandeep. The Prevalence Of Musculoskeletal Disorders And Their Association With Risk Factors In Auto Rickshaw Drivers - A Survey In Gunter City. Int J Physiother 2014; 1(1): 2-9

3. Faisal Ghafoor, studied on prevalence of carpal tunnel syndrome in rickshaw divers in Sargodha (Pakistan) Volume 06 Issue 1 January 2019 https://pen2print.org/index.php/ijr/

4. Clinical orthopedic rehabilitation S. Brent Brotzman second edition page no. 34

5. Therapeutic exercise Kisner 6th edition page no. 398

6. Mahadik VJ, Waingankar P, Anjenaya S, Sanjeev S, Mali K. Cross-sectional Study of Health Status of Auto Rickshaw Drivers in Vashi, Navi Mumbai, India. MGMJ Med Sci 2017; 4(4): 164-170

7. Orthopedic physical assessment David J. Magee 6th edition page no. 473

8. Essential Orthopaedics Maheshwari and Mhaskar $5^{\text {th }}$ edition page no. 303

9. https://www.researchgate.net/publication/24 5027548_Prevalence_of_Carpal_Tunnel_Sy ndrome_in_Motorcyclists 
10. Rhode BA, Rhode WS (2016) Occupational Risk Factors for Carpal Tunnel Syndrome. MOJ Orthop Rheumatol 4(2): 00131. DOI: 10.15406/ mojor.2016.04.00131

11. Lozano- Calderón S, Anthony S, Ring D (2008) The quality and strength of evidence for etiology: example of carpal tunnel syndrome. J Hand Sur 33(4): 525-538.

12. Hill BA (1965) The Environment and Disease: Association or Causation? Proc R Soc Med 58: 295-300.

13. Kumar Rajesh, Kumar Manoj, Beri Rajesh and Arora Shatru Ajat "Analysis of risk factors in Carpal tunnel syndrome among automotive glass channel rubber assembly line workers" International Conference on Advances in Mechanical Engineering,2011,395-407

14. Barnhart Scott, Demers A Paul, Miller Mary, Longstreth WT, Rosenstock, LindaCarpal tunnel syndrome among ski manufacturing workers", Scand J Work Environ Health 1991;17:46-52

15. Yves Roquelaure, Jean Mariel, Corinne Dano, Serge Fanello and Dominique Penneaufontbonne "Prevalence, Incidence
And Risk Factors Of Carpal Tunnel Syndrome In A Large Footwear Factory" International Journal of Occupational Medicine and Environmental Health, Vol. 14, No. 4, 357-367, 2001

16. Ganjane PD, Ganatra M. Prevalence of carpal tunnel syndrome in diamond jewellery workers, Int J Health Sci Res. 2020; 10(6); 57-61.

17. Carpal Tunnel Syndrome Prevention Through Intervention. Occupational health clinic for Ontario workers Inc.

18. Tanaka, S., Wild, D., Cameron, L.L, \& Freund, E (1997). Association of occupational and non- occupational risk factors with the prevalence of self- reported carpal tunnel syndrome in a national survey of the working population. Ant J Ind Med, $32,550-556$.

How to cite this article: Kadam A, Bhalekar G. Prevalence of carpal tunnel syndrome in autorickshaw drivers. Int J Health Sci Res. 2021; 11(8): 35-44. DOI: https://doi.org/10.52403 /ijhsr.20210806 